doi:10.1136/bcr.03.2011.3942corr1

\title{
An iliac bone stress fracture in a basketball player
}

Carlos Vicente Andreoli, Benno Ejnisman, Eduardo Antônio de Figueiredo, Bernardo Barcellos Terra, Alberto Castro Pochini, Moises Cohen, Flavio Faloppa

BMJ Case Reports published online 20 July 2011

The fifth author's name is incorrect, his name is Alberto de Castro Pochini and not Alberto Castro Pochini. 